\title{
Defensive Architecture Mapping: a case study in the city of Curitiba, Paraná, Brazil
}

\author{
Debora Raquel Faria $^{\mathrm{a},}$, , Claudia Robbi Sluter ${ }^{\mathrm{b}}$, Alessandro Filla Rosaneli ${ }^{\mathrm{c}}$, Silvana Philippi \\ Camboim ${ }^{\mathrm{d}}$ \\ ${ }^{a}$ Graduate Program on Urban Planning, Federal University of Paraná, deborahraquel@ gmail.com \\ ${ }^{b}$ Department of Geodesy, Federal University of Rio Grande do Sul, Av. Bento Gonçalves, 9500, CEP 91540-000, Porto Alegre, \\ Brazil, robbi.sluter@ufrgs.br \\ ${ }^{c}$ Department of Architecture and Urbanism, Federal University of Paraná, , Centro Politénico, Jardim das Américas, Caixa Postal \\ 19001, CEP81531-980 Curitiba, Brazil, alessandrofilla@ufpr.br \\ ${ }^{d}$ Department of Geomatics, Federal University of Parana, Centro Politénico, Jardim das Américas, Caixa Postal 19001, CEP \\ 81531-980 Curitiba, Brazil, silvanacamboim@ufpr.br \\ * Corresponding author
}

Keywords: defensive architecture, unofficial mapping, collaborative mapping.

In Brazil, some aspects of the urban reality are not in the official maps. Those aspects are either informal urban elements, built without conventional parameters, or exclusive and exclusionary elements build by a privileged part of society, such as in gated communities. Informal or not, a significant part of these elements does not hold building permits. Furthermore, they are difficult to be represented in maps. The disconnection between the formal and the informal city results in a considerable amount of information that is not represented in official cartography. Thus, the lack of representation of certain urban elements in maps and urban plans is also a socio-spatial segregation symptom. One of the most representative features of Brazilian socio-spatial segregation is the so-called macro urban segregation, in which the higher-class neighborhoods are concentrated in some specific regions, completely separated from the poor communities (VILLAÇA, 2000). This fact explains the reason why the informal settlement areas, like slums, are excluded from many urban zoning plans and formal cartographic representations.

In addition to the irregular settlements, the urban landscape is endowed with smaller scale elements that also generate social exclusion and interfere in the urban and public space, both in material and immaterial ways. Immaterial aspects, such as civility, democracy, and the use of space, are difficult and complex to represent in maps. In turn, the material aspects that cause segregation are not in the maps either. Among the urban reality aspects that are difficult to be mapped, defensive architecture, also named hostile architecture, is the focus of the research work presented here. We consider defensive architecture any construction or object used to control or segregate the urban space, especially the common public space, defining who is allowed to use or access certain areas. Therefore, the elements deployed for this purpose are present in the urban landscape in different forms: protective iron grids, gates, metal spikes, sprinklers, thorn bushes or any other material strategy to control the space.

All these strategies are related to the physical and social segregation of the territory and they assured the use of public space only by some selected groups of people. Nevertheless, the traditional mapping does not follow the fast spread of defensive strategies, making difficult their monitoring and the understanding of their effect on the city. As already mentioned, the architectural elements responsible for exclusionary practices are not registered neither in building permits nor urban plans. Consequently, they are not in any official mapping. Considering that official cartography depicts and represents established policies for the territory occupation - the retrenchment and control to the access and the rights to the territory do not occur only on international borders, the discussion about territorialization, also, implicates excluding or including people within particular boundaries, such as within urban spaces (PETER VANDERGEEST and NANCY LEE PELUSO, 1995).

Motivated by these issues, this research is oriented by how cartography can operate as a spatial analysis instrument to understand the hostile architecture consequences in the public space. Once traditional mapping practices do not include informal elements, such as defensive architecture, our research hypothesis is that the study, classification, and mapping of these elements require diverse arrangements, besides the official ways of representation, such as collaborative mapping and in situ data surveying. The work is in progress and it started in 2017, with the study on the advance of defensive elements over Curitiba city landscape. Curitiba is a municipality in the south of Brazil. In this study, a small area in the city center was defined, and the defensive elements were inventoried and mapped. The region chosen for data surveying was the Sete de Setembro Avenue which has a particular architectural type: public galleries - originally projected to assure the pedestrians a safe walk and to extend sidewalks and public space as well. However, currently, the galleries host many forms of hostile architecture, especially large flowerpots and iron gates that completely close the covered sidewalk. The initial research work results stimulated us to propose a research project about exclusionary architecture and authoritarianism in the center city of Curitiba. Therefore, in 2018, the fieldwork was redone more systematically. At that point, we designed and generated a group of maps. The purpose of this work is to act as a pilot for a larger analysis, throughout the extended center of the city. 

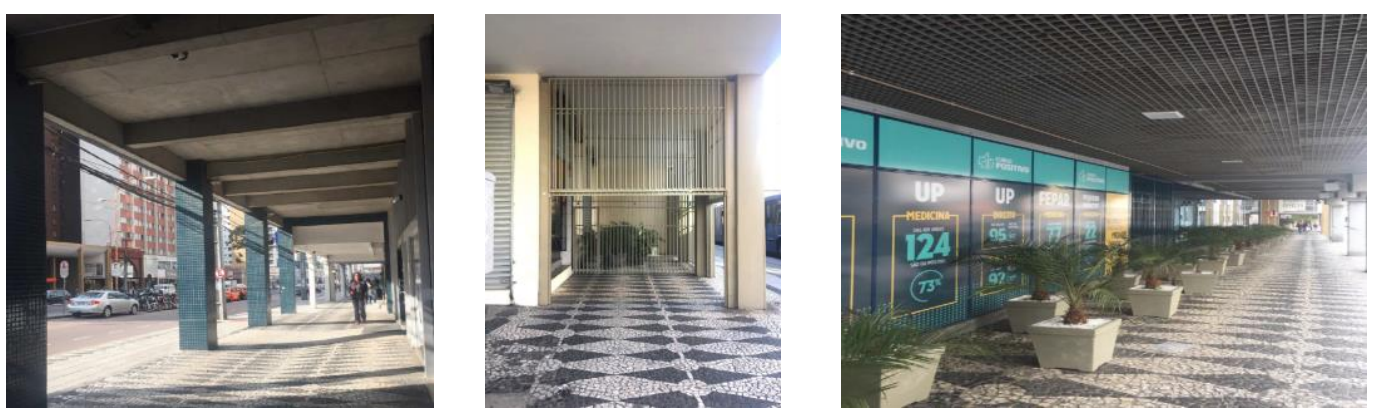

Figure 1. (a) Galleries at Sete de Setembro Avenue, (b) gates closing the galleries, and (c) cement flower pots.

The design and generation of the maps were developed by the theory of thematic mapping. We firstly defined the map users and their needs. Based on the users' needs and the spatial analysis they will perform when the maps are ready, we established which urban features would be depicted on the maps. Knowing the urban features to be mapped we could determine the maps' scales, thus, the level of map generalization. The next step was to defined the features classification. In the end, we developed the cartographic language to design the maps' symbols, and we built the maps. As some results, we understand that the main user of those maps is the researcher responsible for the study "Architecture of exclusion and authoritarianism: control of the use of public space in the city center of Curitiba." The main objective of the research is to evaluate how design, architecture and urban planning contribute to the conformation of exclusionary public spaces in the center of Curitiba. Thus, a GIS software helped to evaluate the positioning of hostile elements, and it allowed understanding which places are most prone to be modified with exclusionary architecture.

The GIS also helps in achieving some specific objectives, such as identifying where the current legal structure influences on the landscape and on the limitation of public space use; verifying how the advance of private spaces over common use spaces, such as residential or commercial buildings, and galleries contribute to the quality of the public space; inventorying elements of hostile architecture (pines on benches, flowerpots on facades, railings) under the galleries of the avenue; and classifying the elements and the degree of restriction they exert under the public space. In order to improve the analysis and data mapping, two groups of hostile architecture classes were defined. The first refers to the type of hostile element, based on the 2017 survey: (1) blockages or private appropriations of public space, private appropriations of covered walks, with tables and chairs used in a restricted and commercial way, as an extension of commercial establishments; (2) hostile furniture, urban furniture placed in front of commercial establishments and residential condominiums (waste bins, bicycle racks, plants pots, skewers and sprinklers); and (3) the gates or grids, which close the galleries partially or totally. The second group os classes is related to the exclusion level that each element provokes: high, medium or low.
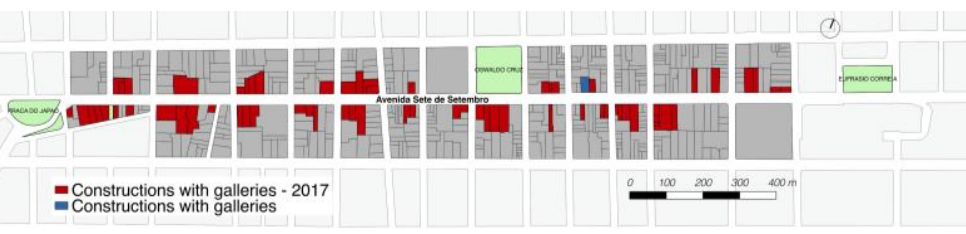

Figure 2. Covered galleries location map.

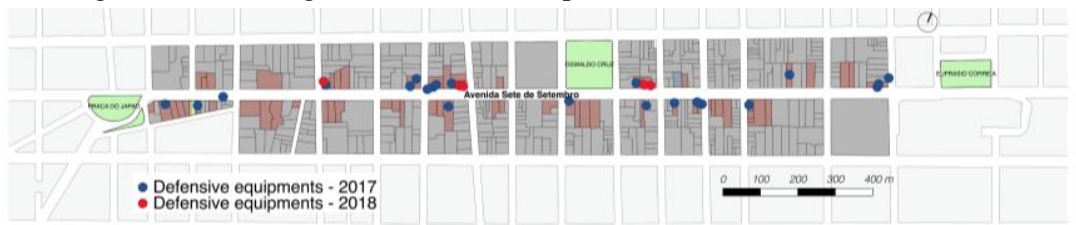

Figure 3. Defensive equipment location map.

As a result of the map design, four maps were created. The thematic maps titles are "covered galleries location", "defensive equipment location", "hostile and defensive equipment", and "degree of exclusion". As an in-progress study, the pilot project described here is fruitful with regards to the possibility of its application in wider study areas, such as entire neighbourhoods. Among the processes that most aided in the studies, the possibility of easy inclusion of points in virtual platforms, like MyMaps or OpenStreetMap was the most productive. This has motivated the creation of collaborative maps (still in development), which enables any person to insert points on them. We also consider that the collaborative process brings benefits not only to facilitate the mapping of elements of exclusion, but to involve the academic community in the research and, at the same time, to raise questions about the process of construction of public space. Furthermore, the official mapping is tied to some agendas, despite the new tools available to democratize cartography. Thus, collaborative mapping is a form of enabling collective construction of a database, besides allowing the integration of several media (text, video, images and audios) with the traditional mapping. 